INTERNATIONAL JOURNAL OF SYSTEMATIC BACTERIOLOGY

Vol. 20, No. 1 January 1970

pp. $61-81$

Copyright 1970, Iowa State University Press

\title{
A NEW SPECIES - MICROCYCLUS FLAVUS
}

H. D. Raj

Department of Microbiology, California State College Long Beach, California 90801

ABSTRACT. A description is given of Microcyclus flavus sp. nov., found in fresh water from deep wells in Long Beach, California, U.S.A., in comparison with Microcyclus aquaticus ( $\varnothing$ rskov).

The genus Microcyclus ( $\varnothing$ rskov 1928,180 ) and its type species $M$. aquaticus are accepted in the Bergey's Manual of Determinative Bacteriology $(1957,253)$. "Microcyclus" (meaning literally "small circles") seems appropriate as a genus name for these Gram-negative bacteria because they have in common formation of closed rings under suitable cultural conditions. However, other morphological variations of the basic ring curvature occur frequently. Several workers (Weibul 1887, 465; Migula 1900, 955; Sturges 1923, 11; Hallock 1960, 404; Gromov 1963, 733; Claus 1967, 254) have reported organisms mostly from soil and water that form ring structures characteristic of the genus Microcyclus. In 1964, during my studies of bacterial ecology of fresh water from deep wells (Water Department Report No. WD546, City of Long Beach, California) an organism was isolated whose morphology indicated assignment to the genus Microcyclus ( $\varnothing$ rskov). Since then, radio-respirometric and electron microscopic studies of this isolate have been made (Raj and Wang 1965, 78; Raj and Kluss 1967, 172; Raj 1968, 44). The studies reported here concern the taxonomic status of this organism believed to represent a new species.

\section{MATERIALS AND METHODS}

For morphological and cultural characteristics, the organisms were grown in tryptone glucose extract agar plus $0.1 \%$ yeast extract (TGEY) medium at room temperature. Also, various commercially available media, such as brain heart infusion (BHI), trypticase soy broth without glucose 
( $T$-soy), Lowenstein-Jensen (LJ) agar, triple sugar iron (TSI) agar and eosin methylene blue (EMB) agar were used.

Microcyclus aquaticus and $M$. flavus were simultaneously compared for various biochemical and physiological properties. All inoculated tubes and plates were incubated at room temperature for as long as 60 days before a test was declared negative. For optimum temperature of growth, inoculated TGEY broth tubes were incubated at $7^{\circ} \mathrm{C}, 22^{\circ} \mathrm{C}$, and $37^{\circ} \mathrm{C}$. For growth in presence of salt, TGEY broth tubes containing various levels of $\mathrm{NaCl}(0,3.5$ and $10 \%)$ were inoculated. Methods to establish biochemical and physiological peoperties (Tables $2,3,4$ ) have been described elsewhere (Manual of Microbiological Methods 1957; Raj et al. 1961, 295). The tests for lipase and oxidase were carried out as described by Gillespie $(1952,187)$ and by Kovacs $(1956,703)$. The utilization of 22 different carbohydrates (Table 4) was tested at $1 \%$ substrate concentration in three different media: phenol red broth base (Difco), purple broth base (Difco) and Hugh and Leifson (1933,24) medium which were used in duplicate tubes for both oxidative and fermentative reactions. Oxidation or utilization of various carbon compounds (Table 3) was examined in a basal medium having the composition of Simmons citrate agar medium (Difco) without citrate and agar.

Antibiotic and Sulfonamide sensitivity tests were done using Bacto-sensitivity disks (Difco) on TGEY medium (Table 2).

Electron microscopy of whole cells and thin sections was done with preparations on 200 mesh copper screen grids on a Hitachi H56 electron microscope. Procedures for fixation, embedding, sectioning, staining (500-600 $\AA$ sections made on Porter-Blum microtone using glass knives) were the same as described by Kellenberger et al. (1958,671). This was followed by post-staining as des $\overline{c r}$ ibed by Millonig $(1961,736)$.

\section{RESULTS AND DISCUSSION}

An isolate forming yellow colonies on a TGEY agar plate after three days' incubation at room temperature was obtained originally from fresh water from a deep well in the city of Long Beach, California. It has been given the name Microcyclus flavus (Latin adj. flavus yellow) because of its typical morphology as implied literally by the genus name and because of its consistently yellow pigment. In order to establish its taxonomic status, it has been compared morpho- 
TABLE 1

Morphological and Cultural Characteristics

\begin{tabular}{|c|c|c|c|}
\hline & Characteristics & M. flavus & M. aquaticus \\
\hline $\begin{array}{l}1 . \\
2 . \\
3 . \\
4 . \\
5 . \\
6 . \\
7 . \\
8 . \\
9 . \\
10 . \\
11 . \\
12 . \\
13 . \\
14 . \\
15 . \\
16 . \\
17 . \\
18 . \\
19 . \\
20 . \\
21 .\end{array}$ & 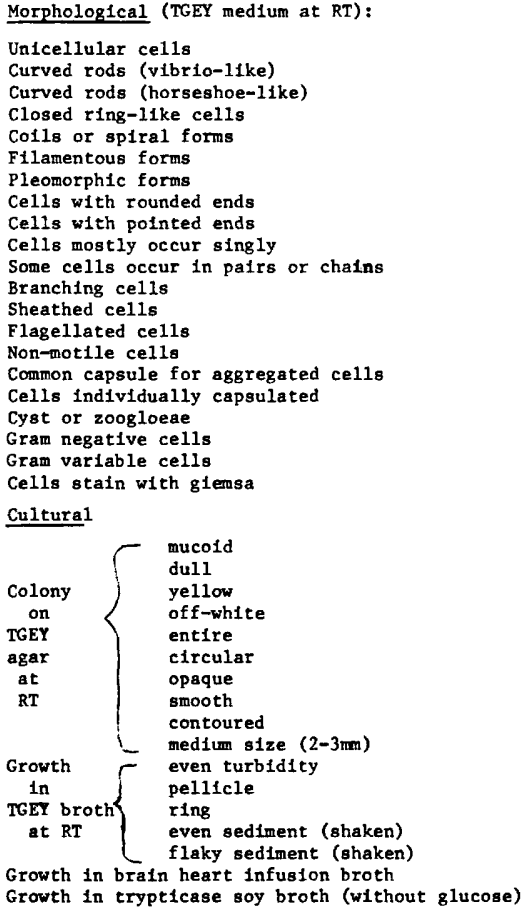 & $\begin{array}{l}+ \\
- \\
+\star \star \\
+\star \star \\
+\star \star \\
+\star \\
- \\
+ \\
- \\
+ \\
+ \\
- \\
- \\
+ \\
+ \\
+ \\
+ \\
- \\
+ \\
+ \\
+ \\
+ \\
+ \\
+ \\
+ \\
+ \\
+ \\
+ \\
+ \\
+ \\
+ \\
+ \\
+ \\
+ \\
+\end{array}$ & $\begin{array}{l}+ \\
+ \text { ** } \\
+* \\
+* \\
- \\
- \\
+* \\
+ \\
- \\
+ \\
+ \\
- \\
- \\
- \\
+ \\
+ \\
+ \\
- \\
+ \\
- \\
+\end{array}$ \\
\hline
\end{tabular}

Number of total similarities $=24$

Number of positive characters shared $=16$ Number of dissimilarities $=14$.

TGEY = tryptone glucose extract (DIfco) medium $+0.1 \%$ yeast extract

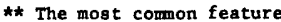

* Seen under certain cultural conditions only 
TABLE 2

Physlological Characteriotics

\begin{tabular}{|c|c|c|c|c|}
\hline & & Characteriatica & M. flavus & M. aquat1cus \\
\hline $\begin{array}{l}39 . \\
40 . \\
42 . \\
43 . \\
44 . \\
45 . \\
46 . \\
47 . \\
48 . \\
49 . \\
50 . \\
51 . \\
52 . \\
53 . \\
54 . \\
55 . \\
56 . \\
57 . \\
58 . \\
59 . \\
60 . \\
61 . \\
62 . \\
63 . \\
64 . \\
65 . \\
66 .\end{array}$ & 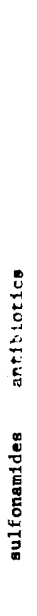 & 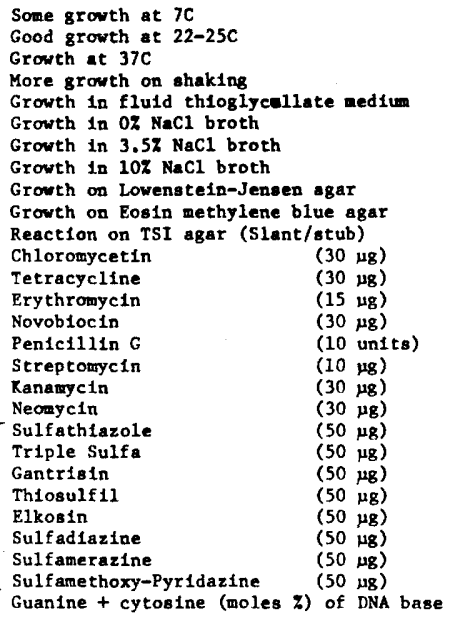 & $\begin{array}{c}+ \\
+ \\
+ \\
+ \\
+ \\
- \\
- \\
- \\
\text { ye110w/ } / 9 \mathrm{ellow} \\
4.0 \mathrm{~cm} \\
4.0 \mathrm{~cm} \\
3.0 \mathrm{~cm} \\
2.5 \mathrm{~cm} \\
2.0 \mathrm{~cm} \\
2.0 \mathrm{~cm} \\
1.5 \mathrm{~cm} \\
8 \\
4.0 \mathrm{~cm} \\
3.0 \mathrm{~cm} \\
3.0 \mathrm{~cm} \\
2.0 \mathrm{~cm} \\
1.0 \mathrm{~cm} \\
1.0 \mathrm{~cm} \\
1.0 \mathrm{~cm} \\
1.0 \mathrm{~cm} \\
51.0\end{array}$ & $\begin{array}{c}+ \\
+ \\
+ \\
+ \\
+ \\
+ \\
- \\
+ \\
+ \\
\text { p1nk/no change } \\
\mathrm{R} \\
4.0 \mathrm{~cm} \\
\mathrm{R} \\
2.5 \mathrm{~cm} \\
\mathrm{R} \\
2.5 \mathrm{~cm} \\
2.5 \mathrm{~cm} \\
1.5 \mathrm{~cm} \\
\mathrm{R} \\
\mathrm{R} \\
\mathrm{R} \\
\mathrm{R} \\
\mathrm{R} \\
\mathrm{R} \\
\mathrm{R} \\
\mathrm{R} \\
67.3\end{array}$ \\
\hline
\end{tabular}

Number of total similaritfes - 11; Number of positive characters shared = 8; Number of dissinflarities $=17$

* Sensitivity tests were done on tryptone glucose agar (Difco) plus 0.1 yeast extract without blood. The results were read after 7 days incubation at room temperature and expressed as diameter of zone inhibition. R = resistant 
TABLE 3

Biochemical Characteristics

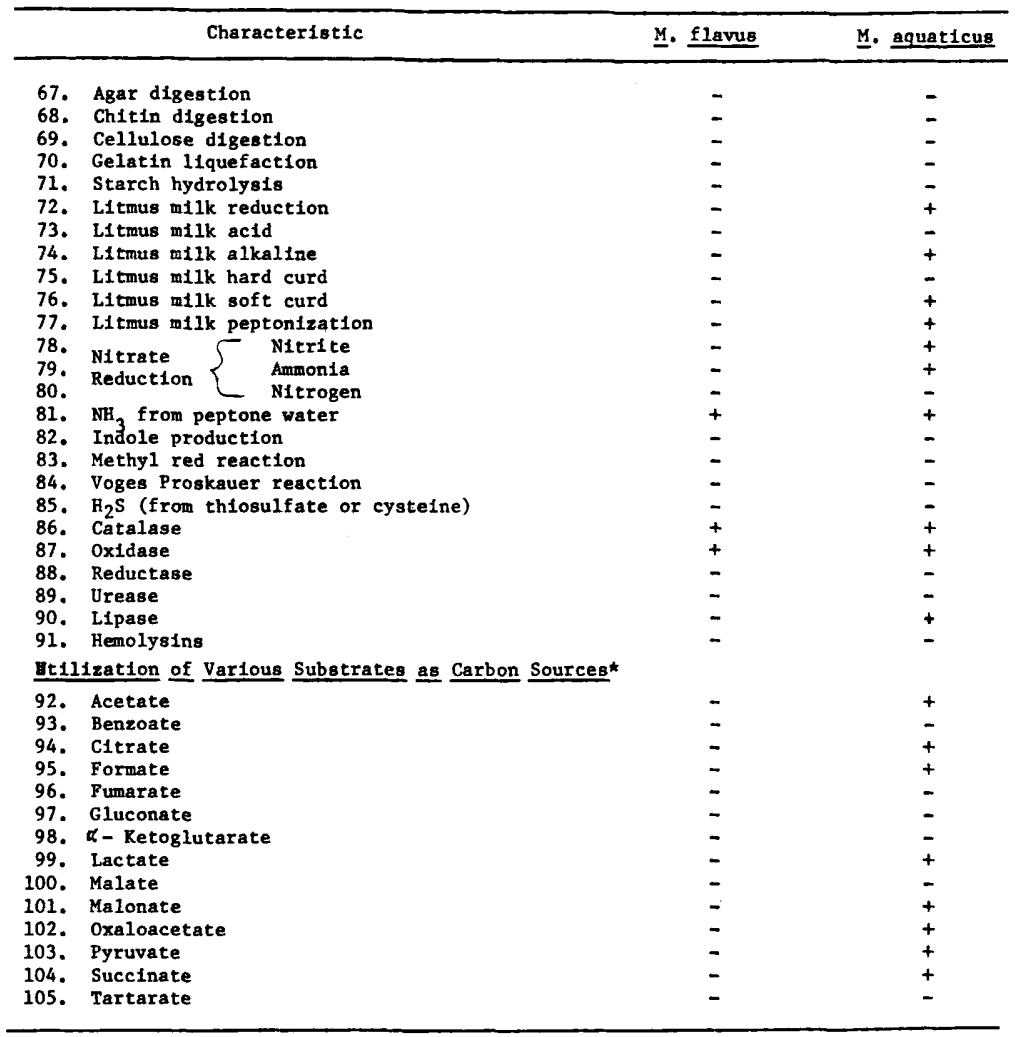

Number of total simflarities = 24; Number of positive characters shared - 3; Number of dissimilarities $=15$.

*Broth base medium used was same as Simmons citrate (D1fco) medium but without

citrate and agar. Fully positive results showing deep blue color (= $\mathrm{pH}>7.6$ )

of the indicator were obtained between 20 - 40 days of incubation at room

temperature. Negative (-) results were recorded after 60 days' incubation. 
TABLE 4

Ut1lization of Carbohydrates when Tested In Three Different Basal Med1a

\begin{tabular}{|c|c|c|c|c|c|c|c|c|}
\hline \multirow[b]{2}{*}{ Carbohydrate } & \multicolumn{4}{|c|}{ Microcyclus flavus } & \multicolumn{4}{|c|}{ Microcyclus squaticus } \\
\hline & $\begin{array}{c}\text { Purple } \\
\text { broth base }\end{array}$ & $\begin{array}{l}\text { Phenol red } \\
\text { broth base }\end{array}$ & $\begin{array}{l}\text { H \& } \mathrm{Lba} \\
(\mathrm{OX})\end{array}$ & & $\begin{array}{c}\text { Furple } \\
\text { broth base }\end{array}$ & $\begin{array}{l}\text { Phenol red } \\
\text { broth base }\end{array}$ & $\begin{array}{l}\text { HदL } L 8 \\
(O x)\end{array}$ & (F) \\
\hline 106. Adonitol & 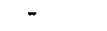 & - & - & - & - & - & - & - \\
\hline 107. Arabinose & a $(25)$ & A (25) & A (12) & - & a (25) & A (25) & A (12) & - \\
\hline 108. Dulcitol & - & - & - & - & - & - & - & - \\
\hline 109. Fructose & - & A (25) & A (17) & - & - & a (25) & A (17) & - \\
\hline 110, Galactose & - & A (25) & A (17) & - & - & - & A (17) & - \\
\hline 111. Glucose & - & A (25) & A (12) & - & - & - & A (12) & - \\
\hline 112. Glycerol & - & - & - & - & - & - & - & - \\
\hline 113. Inu11n & - & \& (12) & A (12) & - & - & - & A (12) & - \\
\hline 114. Inositol & - & - & - & - & - & - & - & - \\
\hline 115. Lactose & - & - & A (12) & - & - & - & - & - \\
\hline 116. Maltose & - & - & A (12) & - & - & - & - & - \\
\hline 117. Mannitol & - & - & - & - & - & - & A (17) & - \\
\hline 118. Mannose & - & A (25) & A (12) & - & - & - & $A(17)$ & - \\
\hline 119. Melezitose & - & - &,$- v$ & - & - & - & - & - \\
\hline 120. Melibiose & - & - & A (17) & - & - & - & A (17) & - \\
\hline 121. Raffinose & - & - & A (12) & - & - & - & - & - \\
\hline 122. Rhamnose & - & - & - & - & - & - & - & - \\
\hline 123. Salicin & - & - &,$- v$ & - & - & - & A (17) & - \\
\hline 124. Sorbitol & - & - & - & - & - & - & A (17) & - \\
\hline 125. Sucrose & - & - & A (12) & - & - & - & A (17) & - \\
\hline 126. Trehlose & - & - & $A(12), v$ & - & - & - &,$- v$ & - \\
\hline 127. Xylose & A (25) & A (25) & A (12) & - & A (25) & $A(25)$ & $A(12)$ & - \\
\hline
\end{tabular}

Number of total imilarities $=16$; Number of positive features shared $=10$;

Number of dissimilartites - 6

$A=$ definite acid production; a * very slight ac1d produced which remained conaiatent up to

60 days; - - no reaction even after 60 days; $V$ - varlable reactions obtained from time to time.

$\Delta$ The numbers in ( ) refer to the number of days taken before the designated reaction was obtained.

- Hugh and Leffson's medium was used in duplicate tubes; one for oxidative (OX) reaction

and the other overlaid with mineral ofl for fermentative $(p)$ reaction. 
logically, culturally, biochemically and physiologically with the type species $M$. aquaticus ( $\varnothing$ rskov strain) of the genus Microcyclus.

Cultural characteristics: As shown in Table 1 and Figure 1, M. flavus forms yellow, circular, convex, smooth, mucoid, viscid colonies of medium size (2-3 mm diameter) with an entire edge and a colorless, narrow peripheral zone (Figure 1B), whereas M. aquaticus forms off-white, circular raised, opaque, butyrous, contoured colonies of medium size on TGEY agar medium (Figure lA). The "fried egg" appearance of contoured colonies of $M$. aquaticus is shown (Figure 1C) in contrast to the smooth colonies of $M$. flavus (Figure 1D). M. flavus yields good growth in TGEY $\overline{\mathrm{broth}}$ mostly as a yellow sediment which on shaking results in even turbidity. In the same medium, $M$. aquaticus produces a pellicle and some sediment which becomes a flaky suspension on shaking. The yellow pigment produced by M. flavus is insoluble in water but soluble in acetone-ethanol mixture and is possibly carotenoid in nature. In contrast to $\mathrm{M}$. aquaticus which is not fastidious in its growth requirements, M. flavus grew not at all or slightly in BHI and T-soy broths. However, neither organism grew in fluid thioglycollate medium (Difco).

Morphological characteristics: A young culture of $M$. flavus grown on TGEY agar slant shows consistently Gramnegative organisms forming horseshoes (0.5-0.8u wide and $3 \mu$ long), closed rings (1.5-2.5 $\mu$ outer diameter) with hollow centers (0.4-1.0 $\mathrm{\mu}$ inner diameter) and other formations resembling letters $\mathrm{C}$ and $\mathrm{S}$ and the number 8 (Figure 2A). Spiral forms (Figure $2 B$ ) or coils of as many as 10 or more cells are also quite commonly found with this organism. Electron micrographs of these various shapes are shown in Figures 3 and 4 . Contrary to $\varnothing$ rskov's observations of $M$. aquaticus, septa between the cells in a coil have been noted in M. flavus (Figures $3 C$ and $3 E$ ). Occasionally a few stretched rods (5-10 $\mu$ long) with or without any bending are seen occurring singly. Such forms are found in pure cultures and are not contaminants. Similar observations were also made by Weibel $(1887,465)$ on his vibrio culture later named Spirosoma nasale by Migula $(1900,955)$. Perhaps the most characteristic form of this organism are the rings which may cover the whole microscopic field (Figure $2 \mathrm{~A}$ ). Electron micrograph of a ring (Figure 3B) shows clearly that the ends of such a cell are positioned one over the other as if it truly represents a closed ring. Figures $4 \mathrm{~B}$ and $4 \mathrm{C}$ show ring cells 


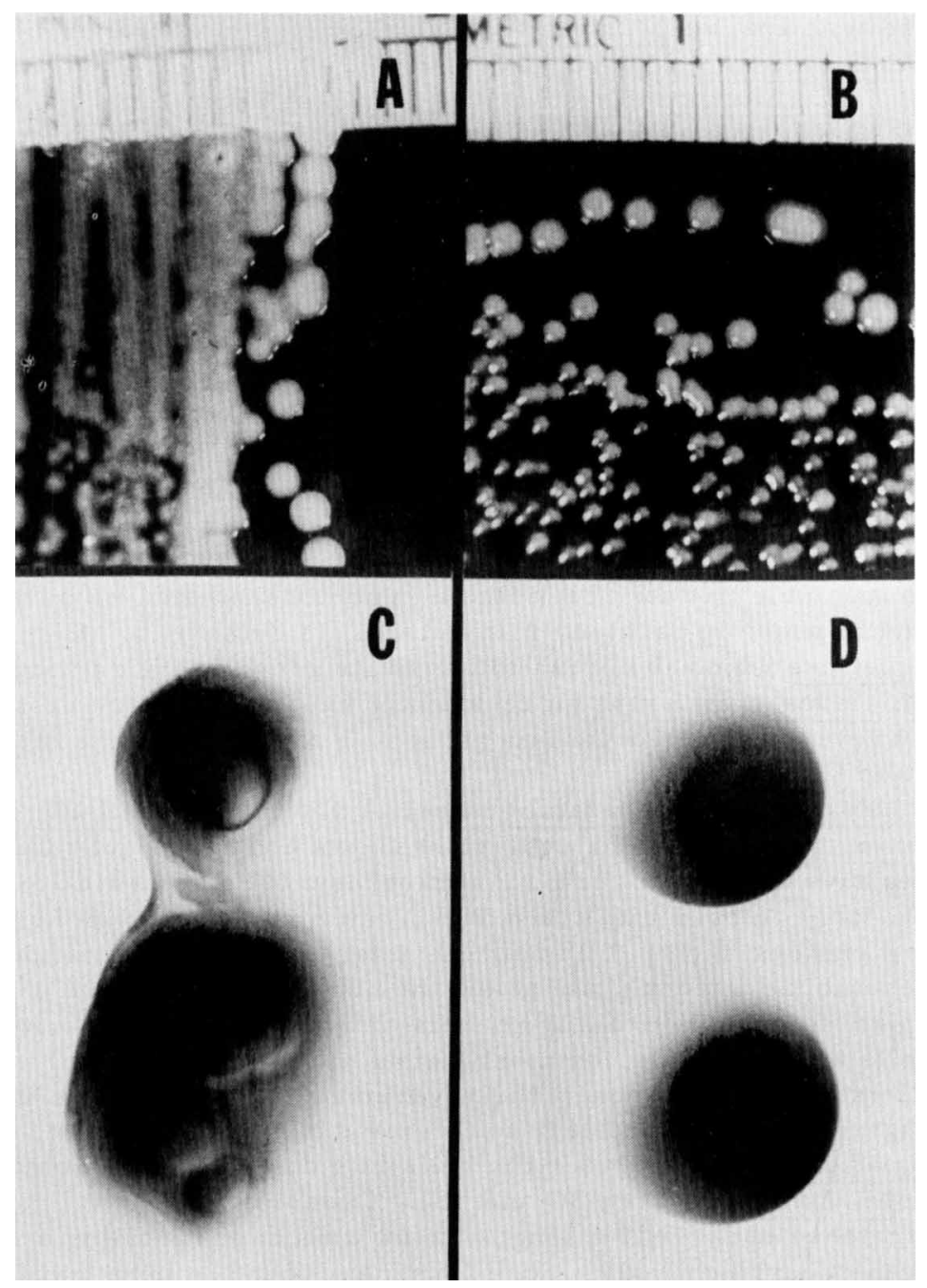

Figure 1. Colonies grown on TGEY agar at room temperature: (A) Colonies of M. aquaticus compared to those of (B) M. flavus (both $\bar{X} 4)$. Also, "fried egg" appearance of contoured colonies of (C) M. aquaticus compared with the smooth colonies of (D) $\underline{M}$. flavus, under transmitted light (both X24). 


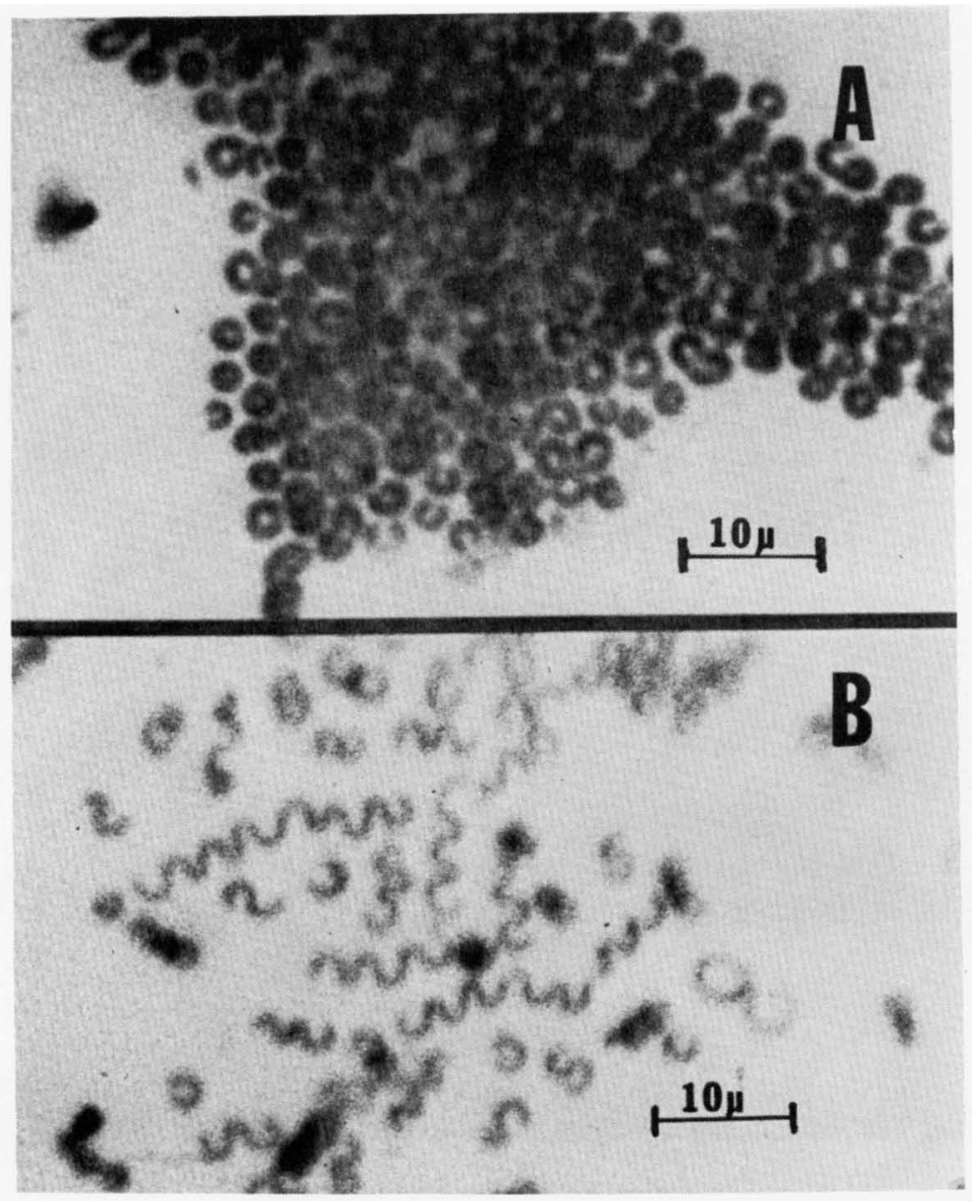

Figure 2. Photomicrographs of normal morphology of $\mathrm{M}$. flavus grown on TGEY agar at room temperature. 


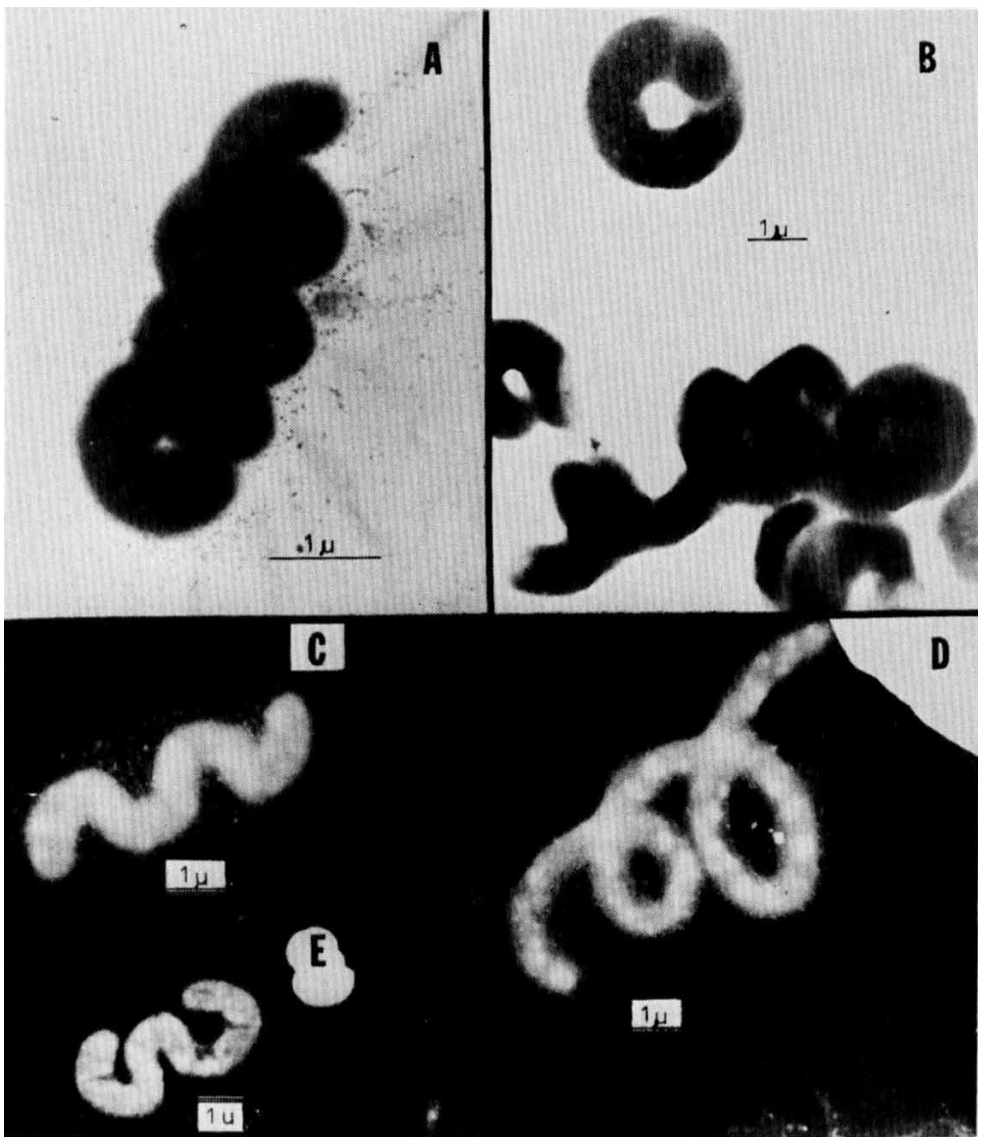

Figure 3. Electron micrographs of various forms of $M$. flavus seen in Figure 2: (A) a coil. (B) a ring and a coil. (C) a spiral; (D) a short coil. (E) two connected horseshoes. 
dividing into two horseshoes. However, it remains conjectural whether the mode of binary fission in this organism follows common cell wall-membrane constriction or transverse septational division known in some, if not most, Gramnegative bacteria (Steed and Murray 1966, 263). The examination of the ultra thin sections of $M$. flavus (Figure 4D) shows that its cell wall has the characteristics of Gramnegative bacteria. It seems to consist of possibly three layers which are quite sinuous and not parallel to its more nearly planar cytoplasmic membrane.

Stained smears of the organism grown in different media showed the same morphological features as described above in practically all instances. However, under certain cultural conditions, M. flavus showed some morphological variations; for example, greater variations in individual cell volume were seen (Figure $5 \mathrm{~A}$ ) when the organism was grown in TGEY broth at $7^{\circ} \mathrm{C}$ than at room temperature. Also when it was grown in MR-VP medium, gelatin medium or Hugh and Leifson (H\& L) medium with glucose, it showed very long spaghetti-like strings (Figures $5 \mathrm{~B}-\mathrm{D}$ ).

Microscopic examination of a Gram-stained smear from a young culture of $M$. aquaticus grown on TGEY agar slant showed very small, slightly curved, Gram-negative rods $(0.7 \times 1.2 \mu)$ (Figure 6A). An electron micrograph of these cells is shown in Figure 6B. However, when the organism is old (15 days) or grown at $7^{\circ} \mathrm{C}$ in TGEY broth or in $\mathrm{H} \& \mathrm{~L}$ medium containing any oxidizable carbohydrate, it shows great morphological variations (Figures $7 \mathrm{~A}, \mathrm{~B}, \mathrm{C}, \mathrm{E}$ ) such as pleomorphism, swollen cells, ring-like structures and horseshoe shapes, as compared to its normal morphology of a slightly curved rod (Figure 7D). From a morphological point of view, there is little resemblance between the two organisms. M. aquaticus normally looks more like a vibrio and very much similar to Hallock's Vibrio alternans, whereas $\mathrm{M}$. flavus seems similar in morphology to Spirosoma sp. strains 1 and 2 of Claus et al. $(1968,26)$. The only feature common to both is the formation of half and full circles. Unlike $M$. aquaticus, $M$. flavus has never been seen to form very small rods $(1 \bar{\mu}$ long) or highly pleomorphic forms. On the other hand, unlike $M$. flavus, $M$. aquaticus does not commonly form rings; in fact, Claus $(\overline{1967,254})$ never succeeded in seeing such ring-like structures in this organism. In my experience, it has never been seen to form spirals or coils. 

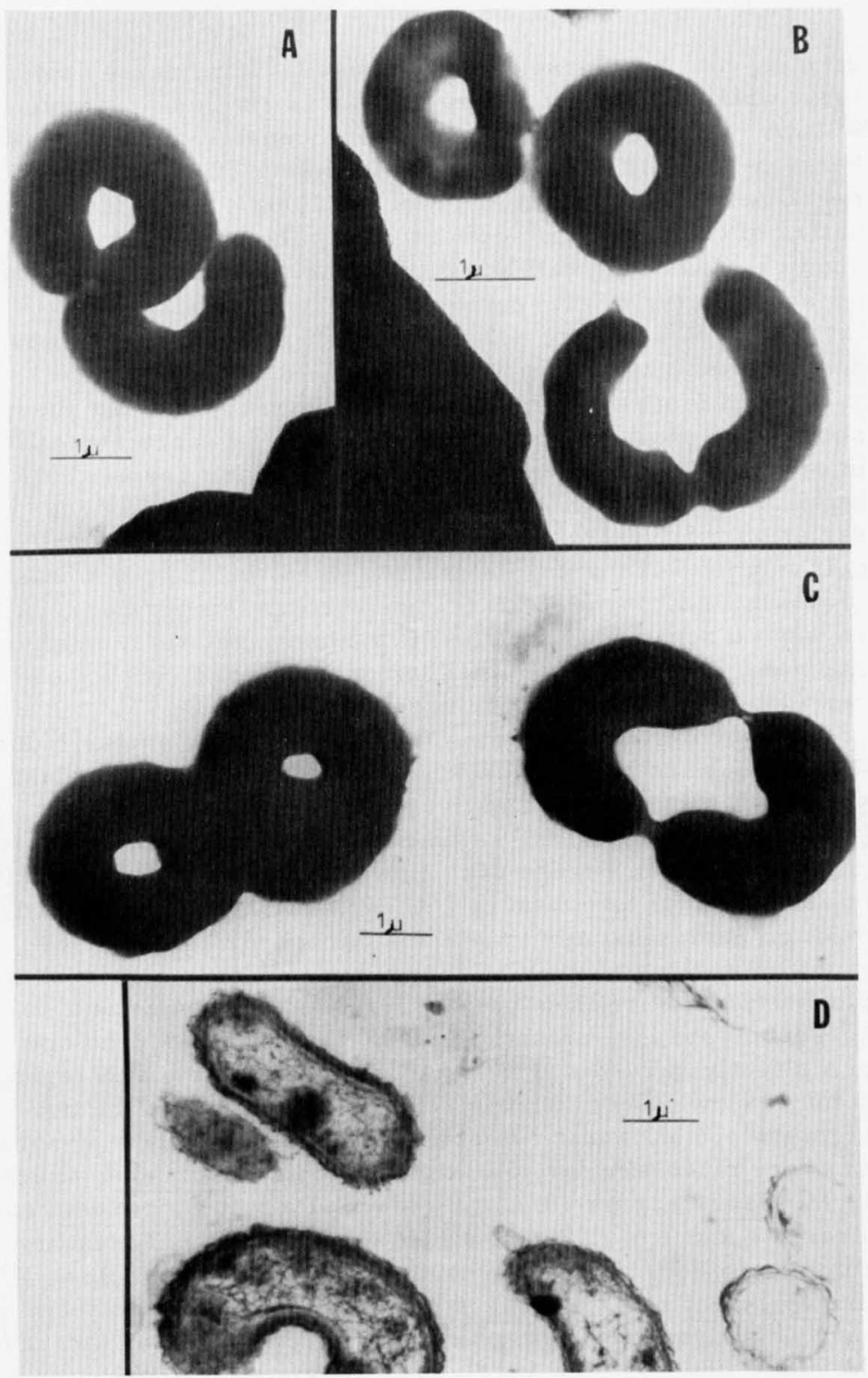

Figure 4. Electron micrographs of dividing cells of $M$. flavus: (A) a ring and a curved cell; (b) rings and a dividing cell; (C) a number 8 formation and a dividing cell; (D) a thin section of a ring cell. 


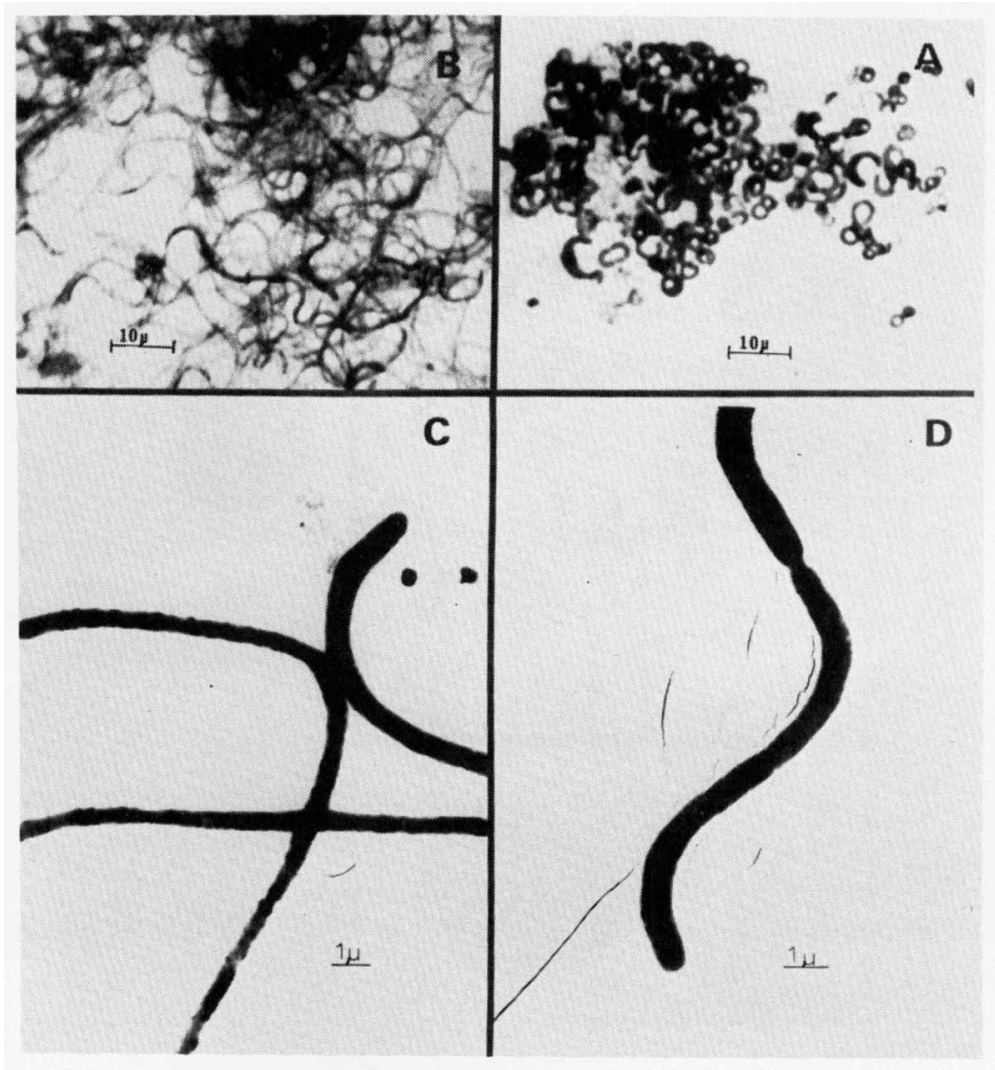

Figure 5. Morphological variations seen in $M$. flavus:

(A) Light micrograph showing cell size variations when grown in TGEY broth at $7^{\circ} \mathrm{C}$; (B) Light micrograph showing filamentous forms when grown in MRVP medium at RT; (C) and (D) Electron micrographs of the filamentous cells seen in (B). 


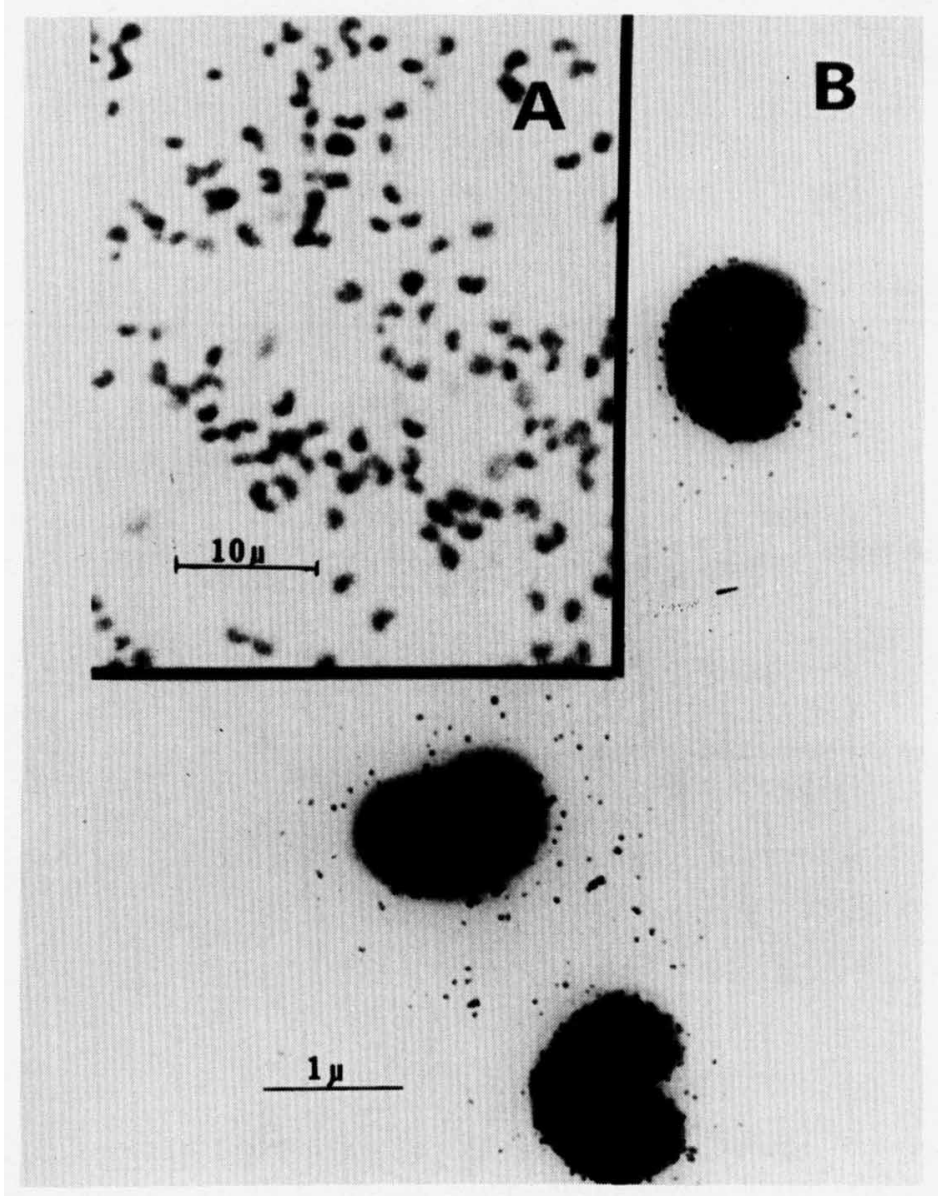

Figure 6. Normal morphology of $M$. aquaticus grown on TGEY agar at room temperature: (A) Photomicrograph; (B) electron micrograph. 


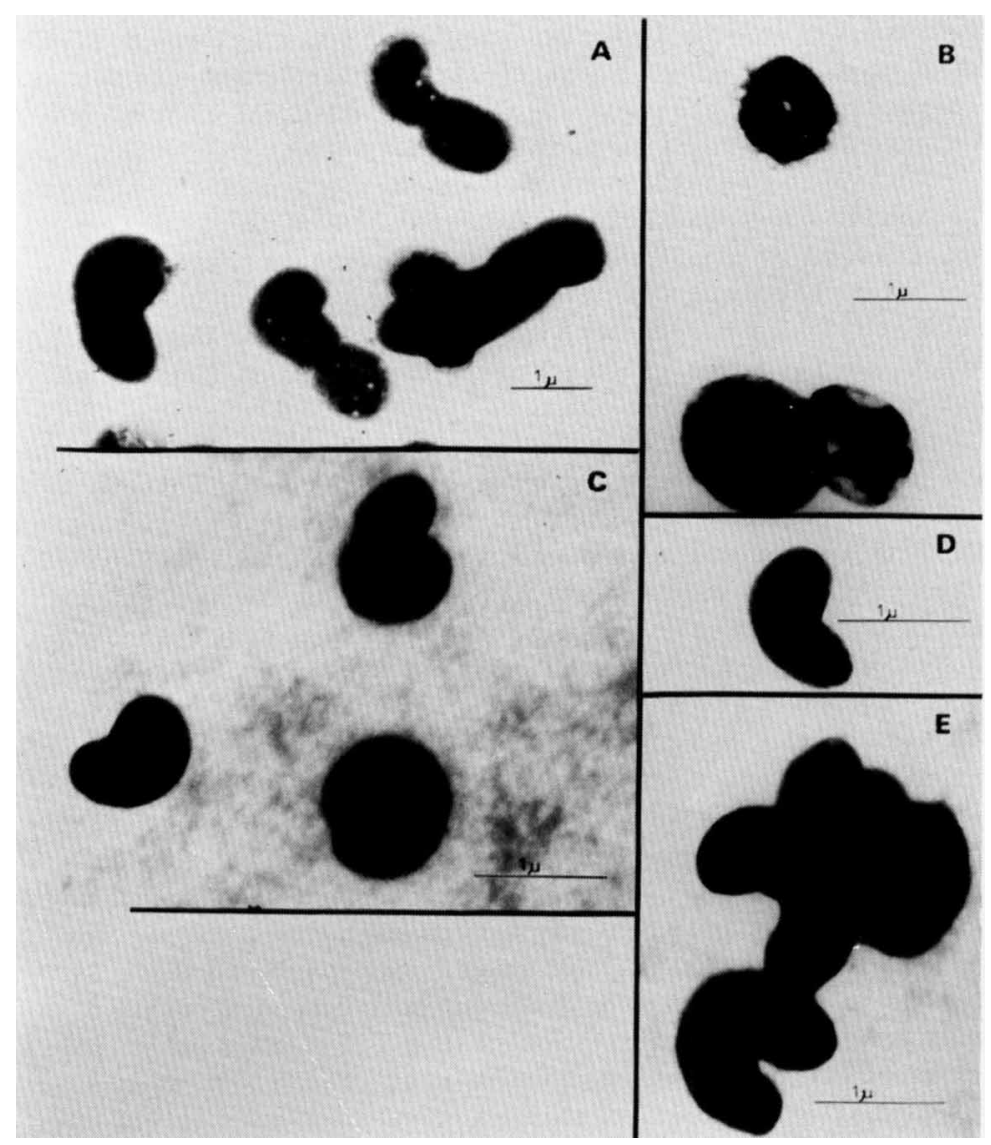

Figure 7. Morphological variations seen in M. aquaticus:

(A) Pleomorphic cells when 15 days old in TGEY broth at room temperature; (B) Doughnut cells when grown in $\mathrm{H} \& \mathrm{~L}$ medium containing arabinose; (C) Swollen cells (E) and Horseshoe shapes when grown in $\mathrm{H} \& \mathrm{~L}$ medium containing xylose as compared to the normal morphology (D) of a slightly curved rod. 
Both the species are nonmotile in motility test agar medium (Difco) as well as in hanging drop preparations. Neither stained preparations for flagella (Leifson's method) nor electron micrographs of these organisms show flagella (Figures 3-7). Capsule staining (Tyler's method) showed both the organisms to be encapsulated when grown in TGEY agar medium. Also, some electron micrographs of $M$. flavus show the presence of capsular material around the aggregated cells (Figures $4 \mathrm{C}$ and $4 \mathrm{D}$ ).

Though in the literature some other organisms such as Cytophaga annulus (Stapp and Bortels 1934, 28), Eubacterium sp. (Bladen et al. 1964, 763), Myconostoc gregarium and Ochrobium tectum are reported to show certain mor phological resemblance to Microcyclus, they seem to bear no close relationship to this genus (Bergey's Manual of Determinative Bacteriology 1957, 260 and 225).

Physiological characteristics: As shown in Table 2, the optimum temperature for growth of both the organisms is room temperature $\left(22-25^{\circ} \mathrm{C}\right)$. However, both failed to grow at $37^{\circ} \mathrm{C}$ but formed slight sediments at $7^{\circ} \mathrm{C}$ in TGEY broth after prolonged incubation. On shaking the sediments, $M$. flavus showed viscid growth compared to the flaky growth of M. aquaticus. When tested for growth in the presence of various levels of $\mathrm{NaCl}$ in TGEY broth, both the organisms did not grow in the presence of $10 \% \mathrm{NaCl}$; while $\mathrm{M}$. flavus failed to grow in $3.5 \% \mathrm{NaCl}$ broth, M. aquaticus grew fairly well producing viscid growth in this medium. Also, when these organisms were cultivated on some of the selective media, M. flavus failed to grow on LJ and EMB media but grew on TSI agar and slowly turned both the slant and the stub yellow only after 17-25 days. Compared to this, M. aquaticus grew on all the three selective media within $\bar{a}$ week and produced pink color on the TSI slant with no color change in its stub even after 25 days. Table 2 presents sensitivities of these organisms to various antibiotics and sulfonamides. While $M$. flavus was sensitive to all the eight

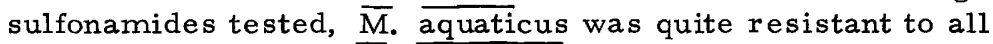
of them. Both the organisms were quite sensitive, in the increasing order, to kanamycin, streptomycin, novobiocin and tetracycline. However, while $M$. flavus was sensitive, in the increasing order, to penicillin G, erythromycin and chloromycetin, M. aquaticus was resistant to them. Of all the antibiotics tested, M. flavus was resistant to neomycin but $M$. aquaticus was somewhat sensitive to it. 
Biochemical characteristics: As shown in Table 3, both the organisms did not hydrolyze any of the polysaccharides tested and failed to produce indole, methyl red reaction, acetyl methyl carbinol, gelatin liquefaction, and $\mathrm{H}_{2} \mathrm{~S}$ from both thiosulfate and cysteine media. However, both produced $\mathrm{NH}_{3}$ from peptone water and possessed catalase and cytochrome oxidase but lacked reductase, urease and hemolysins. M. aquaticus showed lipase activity, reduced the nitrates to $\overline{\mathrm{NO}}_{2}$ and $\mathrm{NH}_{3}$ and caused blue coloration and peptonization of the litmus milk, but $M$. flavus gave completely negative reactions in all these tests. While $\mathrm{M}$. flavus failed to oxidize any of the compounds listed in Table 3, M. aquaticus utilized acetate, citrate, formate, lactate, malonate, pyruvate, oxaloacetate and succinate. However, radiorespirometric studies of $\mathrm{M}$. flavus using various ${ }^{14} \mathrm{C}-$ labeled substrates in the $\overline{\mathrm{T}} \overline{\mathrm{EY}} \overline{\mathrm{me}} \mathrm{dium}$, showed that it utilized acetate and gluconate but not glycine, a-ketoglutarate, methionine and pyruvate. Similar studies made of $M$. aquaticus indicated that ${ }^{14} \mathrm{C}$-labeled gluconate was utilized by this organism contrary to the results shown here. Furthermore, these studies revealed that $M$. flavus metabolizes glucose mainly via the Embden-Meyerhof (EM) pathway and gluconate via the Entner-Douderoff (ED) pathway, both in conjunction with the tricarboxylic acid (TCA) cycle and with some concurrent participation of the pentose phosphate (PP) pathway. $M$. aquaticus, however, shows no evidence of EM pathway but metabolizes both glucose and gluconate via the ED-TCA and PP pathways (Lehner and Raj 1969,36).

The acid production from 22 carbohydrates was tested in three different basal media as shown in Table 4. Both the organisms showed acid reaction from only two carbohydrates (arabinose and xylose) in purple broth base, compared to positive results from three to seven carbohydrates in the phenol red broth base and as many as twelve to fourteen in the $\mathrm{H} \& \mathrm{~L}$ medium. It is thus obvious that $\mathrm{H} \& \mathrm{~L}$ medium is most satisfactory whereas purple broth base is least satisfactory for these tests. $\varnothing$ rskov $(1928,180)$ had reported that $M$. aquaticus could utilize only two carbohydrates (arabinose and xylose) out of the twelve tested. Since there is no specific information in the literature as to the basal medium he used, it seems very likely that a medium similar to the purple broth base was perhaps used which may account for the negative results he reported for many carbohydrates with this organism. Considering only those reactions which were obtained in the $\mathrm{H} \& \mathrm{~L}$ medium, it seems very likely 
that both the organisms can utilize arabinose, fructose, galactose, glucose, inulin, mannose, melibiose, salicin, sucrose and xylose but not adonitol, dulcitol, glycerol, inositol and rhamnose. In addition, M. flavus utilizes lactose, maltose and raffinose but not mannitol and sorbitol which may help to differentiate it from $M$. aquaticus. It may be noted here that with certain carbohydrates (Table 4) variable reactions were obtained with both the organisms when tested from time to time. Both the organisms oxidized carbohydrates in any of the three basal media rather slowly, producing acid but no gas only after prolonged incubation of 20 to 40 days. However, both failed to ferment any of the 22 carbohydrates in tubes of $\mathrm{H}$ and $\mathrm{L}$ medium which were overlaid with sterile mineral oil for fermentative reactions.

Characteristics numbering 127 have been recorded for each organism (Tables 1-4); these include 38 (i. e. $30 \%$ ) morphological and cultural features, and 89 (i.e. $70 \%$ ) biochemical and physiological features. Of these, 77 (36 positive and 41 negative) characteristics are shared which at best account for only $60 \%$ cross-relation between the two organisms. Applying the Adansonian principles of numerical taxonomy and using Sneath's equation $(1957,201)$ for the similarity index (S value) on the basis of only positive features shared, the $S$ value for these organisms is calculated to be about $42 \%$. Since, according to Liston et al. (1963, 1061), this value is far below that expected of strains within the same species, it is clear that $M$. flavus and $M$. aquaticus do not belong to the same species and that $42 \% \mathrm{~S}$ value seems significant enough to justify a separate species status for each organism within the same genus.

Recently Claus and his associates $(1968,26)$ observed, mostly on the basis of deoxyribonucleic acid (DNA) base composition, that the above two organisms represent two different genera. Though the guanine + cytosine (GC) content in the DNA base of M. flavus is $16.3 \%$ less than that of M. aquaticus ( $\mathrm{Table} 2$ ), such a variation is not uncommon among species within the same genus, particularly in the genus Flavobacterium, Pseudomonas, Spirillum, or Vibrio (Hills 1966, 419). If gross morphology and DNA base composition were the only criteria for bacterial classification, then both $M$. aquaticus and $M$. flavus could easily belong to the genus Spirillum or Vibrio (De Ley 1964,17$)$. However, both the Microcyclus species are separated from the above 
genera because they are nonmotile, without flagella and oxidative in their biochemical capabilities besides having characteristic morphological features. If, however, the DNA base composition is emphasized as the only criterion and the characteristic morphology is overlooked, then these organisms may very well be included in the genus Flavobacterium or Pseudomonas (De Ley 1964, 17; Redfearn et al. $\overline{1966,293)}$. Obviously, the DNA base composition cannot be used as a sole determinant in deriving taxonomy of bacteria.

It seems from the reports in the literature, that $M$. flavus and two other isolates, Spirosoma sp. strains 1 and

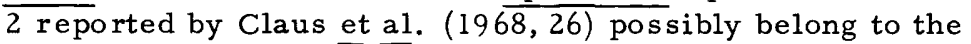
same species. These three organisms are reported to have the same morphological features and the same GC content of $51 \%$. Also, these authors have vaguely suggested that Hallock's Vibrio alternans is possibly related to M. aquaticus. On the other hand, the same authors feel that Gromov's M. major, because of its lower GC content (39.5\%) and peculiar morphology of slightly bent rods with pointed ends, represents a different genus related neither to $M$. aquaticus nor M. flavus. Obviously a detailed comparative study such as presented here is needed of all such organisms before their taxonomic status could be ascertained.

Cultures of the type strain of Microcyclus flavus have been deposited with the Czechoslovak Collection of Microorganisms, Brno, Czechoslovakia as CM No. 2041 and with the American Type Culture Collection, Washington, D. C., as ATCC No. 23276. Also, recently another organism tentatively named as Microcyclus marinus was isolated from the ocean and has been deposited as ATCC No. 25205. M. aquaticus has been deposited as ATCC No. 25396.

\section{ACKNOW LEDGMENTS}

The author is very grateful to Dr. D. Claus, Institut für Mikrobiologie, Universität Göttingen, Germany, for providing me with a subculture of $M$. aquaticus ( $\phi$ r skov strain), Dr. M. Mandel, Department of Molecular Biology, M. D. Anderson Hospital and Tumor Institute, University of Texas, Houston, Texas, for determining the DNA base compositions of M. flavus, Dr. B.C. Kluss, Department of Biology, California State College, Long Beach, California, for doing the electron microscopy of these organisms and $\mathrm{Mr}$. James Snellen, Graduate Student in this department, for his valuable technical assistance throughout this study and the photography for this paper. 


\section{LITERATURE CITED}

Bladen, H.A., M. U. Nylen and R.J. Fitzgerald. 1964. Internal structures of a Eubacterium sp. demonstrated by the negative staining technique. J. Bacteriol. 88:763770 .

Bergey's Manual of Determinative Bacteriology. 1957. Breed, R.S., E.G.D. Murray and N.R. Smith, eds., 7 th ed., The Williams and Wilkins Company, Baltimore.

Claus, D. 1967. Taxonomy of some highly pleomorphic bacteria. Spisy Priorodovedecke Fak. Univ. Brno K40: 254-257.

, J.E. Bergendahl and M. Mandel. 1968. DNA base composition of Microcyclus species and organisms of similar morphology. Arch. für Mikrobiologie 63:26-28.

Deley, J. 1964. Pseudomonas and related genera. Ann. Rev. Microbiol. 18:17-46.

Gillespie, L.A. and $\bar{V}$. G. Alder. 1952, Production of opacity in egg yolk media by coagulase positive staphylococci. J. Path. Bacteriol. 64:187-200.

Gromov, B. V. 1963. A new bacterium of the genus Microcyclus. Dokl. Akad. Nauk. SSSR. 152:733-734.

Hallock, F.A. 1960. The life cycle of Vibrio alternans (sp. nov.). Trans. Amer. Micros. Soc. $\overline{79: 404-411 .}$

Hills, L. R. 1966. An index to deoxyribonucleic acid base composition of bacterial species. J. Gen. Microbiol. 44:419-437.

Hugh, R. and E. Leifson. 1953. The taxonomic significance of fermentative versus oxidative metabolism of carbohydrates by various Gram negative bacteria. J. Bacteriol. 66:24-26.

Kellenberger, E., A. Ryter and J. Sechaud. 1958. Electron microscope study of DNA-containing plasma. II. Vegetative and mature phase DNA as compared with normal bacterial nucleoids in different physiological states. J. Biophys. Biochem. Cytol. 4:671-678.

Kovacs, N. 1956. Identification of Pseudomonas pyocyanea by the oxidase reaction. Nature 178:703.

Lehner, J. and H. Raj. 1969. Radio-respirometric studies of Microcyclus species. Bacteriol. Proc. 1969: Abst. G1 17, p. 36 .

Liston, J., W. J. Wiebe and R.R. Colwell. 1963. Quantitative approach to the study of bacterial species. J. Bacteriol. 85:1061-1070.

Manual of $\bar{M}$ icrobiological Methods. 1957. American Soc. Microbiol. McGraw-Hill Book Co., Inc., New York. 
Migula, W. 1900. System der Bakterien. Handbuch der Morphologie. Entwickelungsgeschichte und Systematik der Bakterien. 2:955-960.

Millonig, G. 1961. A modified procedure for lead staining of thin sections. J. Cell. Biol. 11:736-739.

Ørskov, J. 1928. Beschreibung eines neuen mikroben, Microcyclus aquaticus, mit eigentumlicher morphologie. Zb1. Bakt: I. A Abt. 107:180-184.

Raj, H., W.J. Wiebe and J. Liston. 1961. Detection and enumeration of fecal indicator organisms in frozen seafoods. II. Enterococci. Appl. Microbiol. 9:295-303. and C.H. Wang. 1965. Metabolism studies of Microcyclus aquaticus by radio-respirometry. Bacteriol. Proc. 1965: Abst. P31, p. 78.

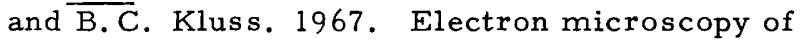
Microcyclus sp. Bacteriol. Proc. 1967: Abst. RT12, p. 172 .

. 1968. A new species: Microcyclus flavus. Bacteriol. Proc. 1968: Abst. G147, p. 44 .

Redfearn, M.S., N. J. Palleroni, and R. Y. Stanier. 1966. A comparative study of Pseudomonas pseudomallei and Bacillus mallei. J. Gen. Microbiol. 43:293-313.

Sneath, P.H.A. 1957. The application of computers to taxonomy. J. Gen. Microbiol. 17:201-226.

Stapp, C., and H. Bortels. 1934. Mikrobiologische Untersuchungen Über die Zersetzung von Waldstreu. $\mathrm{Zbl}$. Bakt. II, Abt. 90:28-66.

Steed, P., and R. G. E. Murray. 1966. The cell wall and cell division of Gram negative bacteria. Can. J. Microbiol. 12:263-270.

Sturges, W.S. 1923. Studies on halophylic microorganisms. The flora of meat curing solutions. Absts. of Bacteriol. 7:11 (Abst. No. 30).

Wiēbel, E. 1887. Untersuchungen über Vibrionen. Zbl.

Bakt. I, Abt. 16:465-472. 